\title{
CON EL INVERNADERO APRENDIMOS TODOS... APRENDIMOS TODO: CONOCIMIENTOS Y PRÁCTICAS SOCIALES DE JÓVENES RURALES
}

\author{
Ana Padawer
}

\begin{abstract}
RESUMO
En este artículo utilizaré el concepto de participación periférica legítima (Lave y Wanger, 2007) para identificar procesos de aprendizaje situado protagonizados por jóvenes rurales que se han incorporado al trabajo familiar. El conocimiento acerca del mundo natural se logra a través de la participación en comunidades de práctica (Wenger, 2001), y por esto último, involucra asimismo aprendizajes sobre el mundo social. El artículo se basa en una investigación de campo antropológica que inicié en 2008 en una zona del Departamento de San Ignacio (provincia de Misiones, noreste de Argentina), localizada en las proximidades de la cabecera departamental. A través del relato de la experiencia de un joven, obtenido a través de observaciones y entrevistas con él, su madre y una de sus hermanas, y que fue elaborado asimismo a partir de la relación con otros testimonios de funcionarios públicos locales, docentes, niños, jóvenes y adultos de la zona, pretendo mostrar cómo algunos jóvenes aprenden, pero también proyectan un futuro en términos educacionales y ocupacionales, a partir de su escolaridad y del involucramiento en actividades productivas familiares.
\end{abstract}

Palavras-chave: Conocimiento. Prácticas Sociales. Escuela Rural. Juventud Aprendizaje.

\section{ABSTRACT \\ WITH THE GREENHOUSE WE ALL HAVE LEARNED... WE LEARN EVERYTHING. RURAL YOUTH'S KNOWLEDGE AND SOCIAL PRACTICES}

In this article I will use the concept of legitimate peripheral participation (Lave y Wanger, 2007) in order to identify situated learning processes which are conducted by rural young people incorporated to family work. Knowledge about natural world is achieved by participating in communities of practices (Wenger, 2003), and by that involves learning about social life. The article is based on an anthropological fieldwork research started in 2008 in a zone of San Ignacio Department (Misiones province, northeast of Argentine), located near of the city head. By a narrative of a young boy's experience, obtained by observations, and interviews with him, his mother and one of his sisters; and that was also made in relation with other testimonies of public administrators, teachers, children, young people and adults of the same zone, I demonstrate how some youth learn, but also project a future in educational and occupational terms, from their school experience and participation in family's productive activities.

Keywords: Knowledge. Social Practices. Rural Education. Youth. Learning.

\footnotetext{
* Doctora en Antropología. Investigadora Adjunta del CONICET - Instituto de Ciencias Antropológicas. Facultad de Filosofía y Letras. Universidad de Buenos Aires. Endereço para contato: Puan 430. Of. 403. Ciudad Autónoma de Buenos Aires. Argentina. apadawer@conicet.gov.ar
} 


\section{Presentación}

Las regulaciones internacionales, principalmente de la Organización Internacional del Trabajo y las Naciones Unidas, promueven la protección de los derechos de la infancia y la juventud, condenando el trabajo infantil y regulando el empleo juvenil ${ }^{1}$. No obstante estos avances normativos, el debate entre posturas abolicionistas y regulacionistas indica que aún persisten dificultades conceptuales y metodológicas en torno al tema (NIEUWENHUYS, 1996; WOODHEAD, 2004; RENDE TAYLOR, 2005).

Sin pretender abordar estas discusiones aquí, y desde la etnografía educativa, entiendo que las posiciones regulacionistas son un punto de partida fructífero para considerar las situaciones en que los niños y jóvenes campesinos realizan actividades productivas en el contexto familiar, entendidas como parte de procesos de producción social de conocimiento. En este artículo utilizaré el concepto de participación periférica legítima (LAVE y WANGER, 2007) para identificar procesos de aprendizaje situado protagonizados por jóvenes rurales que se han incorporado al trabajo familiar. El conocimiento acerca del mundo natural se logra a través de la participación en comunidades de práctica (WENGER, 2001), y por esto último, involucra asimismo aprendizajes sobre el mundo social.

El género, la clase, la etnicidad, el orden de nacimiento en el grupo doméstico influyen en las actividades cotidianas de los jóvenes, y en consecuencia en lo que ellos pueden aprender. En este artículo desarrollaré especialmente como esas condiciones estructurales cambian históricamente en mi contexto de estudio, donde en las últimas décadas la concentración de la propiedad de la tierra se incrementó en razón de la explotación forestal. Esta situación agrava las condiciones de vida precarias de las familias campesinas y reduce las actividades productivas, y por ende los espacios de producción de conocimientos.

A través del relato de la experiencia de un joven, obtenido a través de observaciones y entrevistas con él, su madre y una de sus hermanas, y que fue elaborado asimismo a partir de la relación

\footnotetext{
Para una síntesis de las normativas que en Argentina establecen la protección integral de niños y adolescentes en relación al trabajo ver Padawer (2010).
}

con otros testimonios de funcionarios públicos locales, docentes, niños, jóvenes y adultos de la zona, pretendo mostrar cómo algunos jóvenes aprenden, pero también proyectan un futuro en términos educacionales y ocupacionales, a partir de su escolaridad y del involucramiento en actividades productivas familiares.

Este artículo se basa en una investigación de campo antropológica que inicié en 2008 en una zona del Departamento de San Ignacio (provincia de Misiones, noreste de Argentina), localizada en las proximidades de la cabecera departamental. La misma fue seleccionada por contar con algunas escuelas rurales de población étnicamente heterogénea, como parte de la reflexión de un equipo de investigación que aborda la relación entre procesos educativos y de identificación étnica en distintos contextos y provincias de la Argentina (NOVARO y OTROS, 2011).

La matrícula de estas escuelas está conformada por alumnos de comunidades mbyá-guaranies y de pobladores colonos. En Argentina, la mayoría de las comunidades indígenas mbyà se encuentran en la provincia de Misiones, y cuentan con escuelas en sus propias aldeas; algunas de ellas no tienen acceso a la escuela, y en un pequeño número de comunidades los niños mbyà comparten su escolarización con niños no indígenas. La población que se autodefine como colona, por su parte, suele enviar a los niños a la escuela primaria más próxima a su predio, debiendo trasladarse para estudios secundarios a establecimientos urbanos. En muy pocos casos la oferta educativa de nivel medio se vincula a una formación agraria específica, se trata más bien de bachilleratos que suponen una formación general de preparación para la universidad, que en estos casos casi nunca es posible.

El interés en estas escuelas, que administrativamente se califican como interculturales y bilingües, radica en que en contextos rurales de numerosas provincias, este término remite a establecimientos cuya matrícula es exclusivamente indígena. No es posible desarrollar aquí los procesos que conducen a esta situación; pero es necesario advertir que para mi trabajo, resulta relevante indagar los procesos de identificación acaecidos en escuelas donde esto no sucede, ya que la experiencia cotidiana de educación adquiere características distintivas, dadas 
por contrastes y asimilaciones entre los niños que adscriben a una $\mathrm{u}$ otra identidad, dentro y fuera de la escuela donde se encuentran y relacionan entre si.

Los establecimientos de la zona son típicamente rurales en su organización y dimensiones: cuentan con menos de 100 alumnos y funcionan con agrupamientos multiedad, disponiéndose de auxiliares indígenas para asistir a los ingresantes con poco dominio del castellano. El trabajo de campo se focalizó inicialmente en una de las escuelas, cuya sede cuenta con población indígena y colona de similares proporciones, y con dos aulas satélites exclusivamente indígenas. Dado que el propósito del estudio es conocer las experiencias formativas de niños y jóvenes derivadas del trabajo en los predios familiares o comunitarios, el acceso a la escuela permite ver estos conocimientos puestos en relación con la propuesta escolar. He realizado observaciones de clases de los niños entre 10 y 12 años, y el contexto escolar me ha permitido llevar adelante técnicas experimentales para abordar las actividades cotidianas de los niños a través de la solicitud de dibujos, narraciones, free listing y otras tareas propuestas a los alumnos.

Si bien diseñé el acceso a las familias a través de la escuela, mi trabajo de campo se orientó a reconstruir las actividades prediales de niños, así como de jóvenes egresados de la escuela. La elección de los alumnos mayores se debe a que el trabajo de investigación inicialmente mostró que, en el marco de la escolaridad primaria, es a partir de esta edad cuando se despliegan un amplio rango de responsabilidades en el trabajo del campo. En la casi totalidad de los hogares he registrado las tareas que los alumnos tienen diariamente a cargo a través de fotografías y video, y he entrevistado a los miembros adultos a fin de reconstruir las actividades económicas del grupo doméstico. Asimismo entrevisté a los referentes mbya-guarani vinculados a la escuela, al personal docente, las autoridades locales y otras figuras relevantes en relación a las actividades productivas.

En este artículo focalizaré el análisis en los jóvenes colonos, ya que como he señalado en otro artículo, aunque se ha avanzado poco en términos gubernamentales para potenciar la transmisión intergeneracional de conocimiento indígena, la normativa internacional ya contempla la dimensión educativa de las actividades productivas consideradas "tradicionales" (PADAWER, 2010). Para los campesinos, cuyas condiciones de vida y conocimiento local son en ciertos aspectos similares (y se encuentran en relación), la normativa aun no ha avanzado de modo acorde.

\section{El poblamiento y las actividades pro- ductivas en San Ignacio}

El departamento de San Ignacio está localizado al sudoeste de Misiones, siendo ésta la provincia ubicada en el extremo NE de la Argentina, con una extensa frontera con Brasil y Paraguay. Las actividades productivas están asociadas al bioma de la selva paranaense, y su ubicación es estratégica su ubicación por la proximidad a la capital provincial $(60 \mathrm{~km})$, en el trayecto de una ruta nacional transitada frecuentemente por el turismo que se dirige al Parque Nacional Iguazú, los transportistas de yerba mate, te y las actividades forestales extractivas.

Si bien el foco de este artículo son las familias de colonos, es importante referir brevemente a las relaciones interétnicas que se verifican en este contexto, así como su profundidad temporal. Los datos históricos muestran que a comienzos del siglo XVI los guaraníes eran un grupo étnico demográfica y geográficamente extendido, con una población de más de dos millones de personas habitando porciones de los actuales territorios de Argentina, Uruguay, Brasil, y Paraguay. A partir del contacto con los europeos, la población disminuyó drásticamente, a causa de la introducción de enfermedades infecciosas, la guerra y la esclavitud (NOELLI, 2004, p. 17).

Los guaraníes, base cultural, lingüística y demográfica de la población indígena contemporánea de la región, incluyen cuatro parcialidades tradicionalmente designadas como Mbya, Pai-Taviterá, Avá-Chiripá y Aché-Guayaki. Se supone que los mbyà actuales son los descendientes de aquellos indígenas que lograron permanecer al margen del experimento colonial desarrollado por los jesuitas entre los siglos XVI y XVIII, a través de la constitución de pequeñas comunidades refugiadas en la selva que implicaron la construcción de una identificación social definida por la confrontación y el 
contraste con el mundo de los extranjeros, primero blancos y luego de sus descendientes mestizos (BARTOLOMÉ, 2004).

Posteriormente, el establecimiento de los mbyà en el actual territorio argentino se definió en interrelación al avance de las fronteras de poblamiento de la sociedad nacional a fines del siglo XIX y primeras décadas del siglo $\mathrm{XX}$, provocando una progresiva dispersión y desgranamiento de las aldeas (GOROSITO, 2006). Es en este momento cuando se asienta en territorio misionero la población identificada como colona, a través de un proceso de asentamiento poblacional organizado principalmente por el Estado, el que se realizó sobre las tierras remanentes de una venta a unas pocas decenas de grandes compradores. El proceso de colonización se extendió hasta casi la mitad del siglo XX, y como resultado de ambos procesos, se generó una estructura de la propiedad de la tierra en la que coexistían grandes latifundios y un número importante de propiedades familiares surgidas del padrón de colonización, fijado en 25 has por familia (RICOTTO y ALMEIDA, 2002).

Si bien en un principio los colonos se dedicaron exclusivamente a la producción de yerba mate, incorporaron sucesivamente el tung, el tabaco y el té, producciones que se dieron simultáneamente a la explotación forestal efectuada por los grandes propietarios. De esta forma la sociedad agraria misionera no-indígena está compuesta actualmente por el ocupante o campesino-agricultor familiar con 1 a 10 has, de origen criollo o inmigrante brasilero y paraguayo; el colono-agricultor familiar con 25 a 50 has, en su mayoría de origen inmigrante europeo; el estanciero o productor ganadero, con terrenos entre 100 y 1.000 has; y el latifundista extractivista, cuya propiedad es mayor a 1.000 has. (REBORATTI 1979; JAUME et al 1989; BARTOLOMÉ 2000; BARANGER 2008; OTERO 2008)

En San Ignacio hay actualmente una alta concentración de pequeñas comunidades mbyàguaranies. La zona de estudio incluye a 8 de las 16 aldeas identificadas en esa jurisdicción recientemente: Andresito, San Ignacio Miní, Katupyry, Kokuere'i, Pindoju (Pindoity), Ñu Porá, El Tacuaral y Ivy Poty, y en cada una de ellas la población puede oscilar entre las 20 y 100 personas (Centro de Trabalho Indigenista, 2008). Estas comunidades se encuentran próximas a la ciudad cabecera (a no más de $20 \mathrm{~km}$ ), por lo que se encuentran en un espacio rural que ha sido objeto de considerables transformaciones en relación a las actividades económicas desde hace tiempo.

En el caso de los colonos, la zona de estudio fue definida asimismo por su proximidad con la ciudad cabecera. En el Departamento de San Ignacio existen 8 ciudades que son sede municipal, la mayor parte de las cuales fueron fundadas en la década del 50 en el trazado de una ruta nacional. Sin embargo, dos ciudades son anteriores: la cabecera departamental, San Ignacio, fue fundada en 1693, y Corpus, localidad próxima, en 1882 (GOBIERNO DE MISIONES, 2008). Como resultado de este proceso de poblamiento, su antigüedad y su carácter político administrativo, casi el $60 \%$ de la población del municipio de San Ignacio es urbana; este estudio está localizado las colonias más próximas a la ciudad: Aparicio Cue e Invernada.

Teniendo en cuenta el patrón de asentamiento ya mencionado, los datos estadísticos recientes permiten corroborar que en las zonas rurales de San Ignacio existe una importante concentración en la explotación de la tierra: casi el $30 \%$ de la superficie productiva correspondía en 2002 a explotaciones típicas de colonos y ocupantes, más del $45 \%$ con explotaciones definidas como estancias y poco más del $25 \%$ correspondía con latifundios (GOBIERNO DE MISIONES, 2008, p. 340-341).

Esta estructura está cimentada en los procesos históricos ya mencionados, pero asimismo en la situación actual han incidido cambios que se verificaron en las últimas décadas. En primer lugar, el quiebre en la estructura política institucional y en las modalidades del proceso de acumulación de la sociedad argentina inaugurado en 1976, que produjo una crisis agrícola y mayor concentración de la propiedad de la tierra, acelerándose el proceso de descampesinización (MANZANAL y ROFMAN, 1989; CRAGNOLINO, 2006). En segundo lugar, el reposicionamiento de los productos agrícolas en el mercado mundial en los últimos años, que ha dado lugar a modalidades de producción agroindustrial, la que afecta diferencialmente a pequeños productores y poblaciones indígenas en sus formas de acceso a los recursos, empleo y sobrevivencia (RAMOS, 2006; NE- 
IMAN et al. 2002; BIDASECA y MARIOTTI 2001; GORDILLO, 1995).

En Misiones, el complejo agroindustrial que se desarrolló con más fuerza en los últimos treinta años es el tabacalero, que reemplazó a la producción yerbatera en crisis desde la década del 90 . En la zona de estudio, la reorganización productiva se ha orientado a la diversificación, destacándose la producción hortícola bajo cubierta, los sistemas silvopastoriles, la apicultura y piscicultura, así como varios intentos de explotación de especies vegetales nativas. Además de las dificultades de reorientar la producción, se han multiplicado los conflictos con los propietarios de bosques nativos, quienes en su momento habían facilitado el usufructo de los colonos y ocupantes pero con el desarrollo de explotaciones forestales de especies exóticas por parte de capitales concentrados, reclaman las tierras ahora altamente valorizadas (SCHIAVONI, 1995 y 2008; FERRERO, 2006).

\section{Conocimientos y prácticas sociales}

Uno de los aportes más relevantes de la antropología a los estudios educativos ha sido la distinción entre la persona educada y la persona escolarizada (LEVINSON y HOLLAND, 1996). Sólo si admitimos que los sujetos sociales aprendemos en distintos contextos, a lo largo de toda nuestra vida, y que consecuentemente hay y ha habido otras maneras de aprender, es posible entender la participación de los niños y jóvenes en la producción familiar doméstica como una experiencia formativa.

El foco en los procesos de aprendizaje a través de prácticas sociales deriva de una recuperación del concepto de adiestramiento (apprenticeship). Lave y Wanger señalan que las aproximaciones clásicas al concepto refieren a una serie de características: una actividad ligada a la producción artesanal, individual y en pequeños grupos; la utilización de herramientas simples y conocimiento tácito; la división del trabajo basada en la adaptación individual y la prevalencia de códigos de protección tradicionales. Por el contrario, sugieren que esta formulación refleja solo una de las formas históricas, tradiciones culturales y modos de producción que asume el adiestramiento. Por ello, este proceso de aprendizaje no es inherentemente explotador ni igualitario, sino que debe analizarse bajo qué forma de organización política y social se desarrolla en cada contexto, bajo que principios formativos se articula y se realiza (LAVE Y WANGER, 2007, p. 62-63).

La noción de adiestramiento proporciona la posibilidad de atender a la relación entre conocimiento y prácticas sociales, de forma de que la noción de aprendizaje situado puede ampliarse asimismo: ya no refiere solo a sus coordenadas espacio temporales y su carácter intersubjetivo y contextual, sino que enfatiza su carácter de actividad situada. Este foco en las prácticas sociales involucradas en los procesos de conocimiento no necesariamente reduce sus alcances: el denominado conocimiento general, con el que suele contraponerse el conocimiento situado, es asociado a representaciones abstractas y descontextualización; sin embargo, desde la perspectiva de Lave y Wenger las representaciones abstractas siempre adquieren significado en un contexto, y son en sí mismas adquiridas en circunstancias específicas (2007, p.33).

El involucramiento en prácticas sociales que están constituidas por procesos de aprendizaje permite a estos autores formular el concepto de participación periférica legítima, que refiere al proceso mediante el cual los novatos se vuelven parte de una comunidad de práctica, donde están implicadas las intenciones del sujeto de aprender, y el significado del aprendizaje es configurado a través del proceso de volverse un participante completo en una práctica sociocultural (LAVE y WENGER, 2007, p. 40). Este concepto está vinculado al de participación guiada (ROGOFF et al, 1993, p. 6), que apoyado en Vygotsky, ha permitido reformular el estudio del conocimiento infantil en distintos contextos socioculturales; desde esta perspectiva, los niños avanzan en el entendimiento en un proceso creativo mediante el cual transforman aquello que conocen y el propio mundo, al tiempo en que se vuelven progresivamente participantes de las actividades de su comunidad.

El concepto de ambiente en relación al desarrollo infantil es clave para entender esta definición relacional del entorno de los niños: así como la estructura externa del ambiente inmediato de un niño puede ser constante, la forma en que diferentes niños de diferentes edades se relacionan con ese 
ambiente difiere en forma notable. Tomando el lenguaje, por ejemplo, un bebé apenas comienza a otorgar sentido a ese mundo de habla más próximo, mientras que un niño de diez años es participante activo del discurso de la familia (VYGOTSKY [1935], 1994, p. 339).

La experiencia personal se vincula con la estructura ambiental, donde las actividades cotidianas se realizan en el marco de diferentes relaciones entre los sujetos; el ambiente estructurado es un recurso para las experiencias de vida y significados elaborados por los niños. El proceso de generalización involucrado en la construcción de significados sobre cualquier experiencia personal específica con una estructura ambiental, prepara al niño en desarrollo para confrontaciones futuras en diferentes ambientes; por ello es la experiencia personalmente significativa la que surge en la interacción niñoambiente, las funciones psicológicas superiores emergen primero del comportamiento colectivo del niño, en la cooperación con otros, y son luego internalizadas (VAN DER VEER y VALSINER, 2006, p. 343-344).

A diferencia de los enfoques más a-históricos que prevalecen en el uso de las nociones de transmisión e internalización, la participación periférica legítima y la participación guiada permiten entender el proceso de aprendizaje compartiendo la naturaleza conflictiva de las prácticas sociales, de manera que las relaciones entre aprendices y veteranos son parte de procesos de transformación social acaecidos a nivel cotidiano. No se trata solamente de ser capaz de involucrarse en nuevas actividades o dominar nuevos conocimientos, sino poder establecer nuevas relaciones habilitadas por ese dominio, por las cuales el sujeto participa en la producción y reproducción de las estructuras de las comunidades de práctica en las que se ve involucrado (LAVE y WENGER, 2007, p. 48).

Por ello, la idea de comunidades de práctica, en las que los sujetos pueden ocupar posiciones de centro y periferia, supone asimismo que estos procesos involucran relaciones de poder y hegemonía: la participación completa implica un dominio cercano del conocimiento o prácticas colectivas para los cuales debe haber grados de adquisición atribuibles-accesibles a los novatos. No obstante, el carácter periférico alude a un acceso progresivo a fuentes de entendimiento a través del involucramiento creciente donde inciden la legitimidad, la organización social y el control de recursos (LAVE y WAGNER 2007, p. 37).

En la consideración de estos procesos en términos de relaciones intergeneracionales en contextos de desigualdad social, las tareas que los niños y jóvenes realizan mediante su participación periférica en actividades para la reproducción familiar doméstica pueden constituir experiencias formativas pero, también, constituir modalidades de trabajo infantil. En este sentido, distintos autores advierten que las primeras son condición para la transmisión de un patrimonio de saberes y la construcción de sucesores en la actividad desarrollada por los adultos del grupo doméstico, y se vinculan con las expectativas de formación de las unidades familiares; las segundas implican la venta de la fuerza de trabajo y la consecuente extracción de un plusvalor por parte del adulto, situaciones de riesgo y escasas o nulas situaciones de aprendizaje de un oficio o habilidades (LEITE DE SOUSA, 2004; NEVES, 1999; JACQUEMIN, 2004).

\section{Simón y su familia}

Simón tiene actualmente 19 años, es el segundo varón de una familia de cuatro hermanos, y su hermana más pequeña asistía en 2010 a la escuela rural donde se focalizó este estudio. Sus padres migraron de la ciudad al campo hace diez años; si bien algunos de sus bisabuelos y abuelos eran de la chacra, para sus padres así como para Simón y sus hermanos los conocimientos implicados en el trabajo en el campo se constituyeron objeto de aprendizaje reciente.

A partir del relato de su madre, la historia de las cuatro últimas generaciones de la familia de Simón muestra una serie de traslados entre ciudades pequeñas, migraciones interprovinciales y desplazamientos entre el campo y la ciudad en ambas direcciones, lo que permite complejizar el proceso de descampesinización anteriormente mencionado. Si bien el proceso de concentración de las explotaciones rurales y la migración consecuente a las ciudades es una tendencia general, la falta de oportunidades y las problemáticas sociales urbanas son 
motivaciones para que familias como la de Simón intenten volver al campo que dejaron sus ancestros. Esta vuelta al campo plantea problemas relativos al conocimiento del mundo natural y social particulares, ya que se han producido discontinuidades de prácticas sociales vinculadas a la agricultura y la cría de animales entre las generaciones.

La familia de Simón dispone de 50 hectáreas de su propiedad, lo que la ubica en el rango estadístico de colonos. La madre de Simón me explicó que su marido "desde siempre tenía el sueño de vivir en una chacra"; si bien en su infancia pasaban fines de semana en un predio propiedad de su suegro, ya siendo adulto y con la profesión de carpintero es cuando el padre de Simón recibe la herencia familiar de un campo en San Ignacio. Ella, ama de casa criada en la ciudad, aprendió en ese momento a ordeñar, elaborar derivados de la leche y conservas. Su marido, quien complementará de ahí en más las tareas de carpintería en la ciudad con una producción predial crecientemente diversificada, también inició un camino de aprendizaje, que para ambos continúa hasta hoy:

Lo primero que hicimos fue plantar. La gente acá suele plantar maíz, mandioca, zapallo, nosotras ya plantamos además soja, maní, caña de azúcar. De entrada lo primero fue la huerta, con todo lo que se planta: lechuga, repollo, zanahoria, perejil, acelga, cebollita. (...) Ahora la huerta dejamos así, porque mi esposo desde el año pasado se dedicó a hacer invernadero. Después empezamos con ganadería, apicultura. Vacas, leche, rápido enseguida lo que primero conseguimos fue la vaca lechera. Empezamos con tres vacas pero ahora tenemos creo que 18, entramos con un plan del gobierno que nos ayudó.... Además con apicultura, que empezamos nosotros solos y después entramos en un plan del gobierno también, hicimos un curso. Al finalizar el curso a mi hijo le regalaron todo el equipo, los trajes... (...)

El año pasado mi marido, con mi otro hijo que también salió de la escuela y aprendió todo lo que es vivero, entonces pedimos prestada plata para una cuñada, un cuñado... y se hizo un invernadero, por cuenta nuestra nomás. Plantamos tomate. Con el aprendizaje de mi hijo, lo que vio todo ahí en la escuela, (...) ahí empezó: "papi, vamos a hacer un invernadero". Después cuando empezaron a hacer, yo creí que era forrar un techo con plástico nomás.... Y no! Era el abono, que había que quemarle, preparar el terreno, desinfectarle, yo que sé. (...) Se sufrió, porque había que devolver la plata, pero cuando salieron los tomates fue una maravilla. (...) Con eso se pudo comprar la moto para salir a vender, se devolvió la plata a los cuñados, todo. Con el invernadero aprendimos todos... Aprendimos todo: los remedios, algún insecticida por los bichitos, de eso se encargaba Simón, o mi esposo. Por ejemplo: atar los tomates. Yo ni idea, sabía que tenía que poner un hilo especial de nylon que se compra, fuerte. A medida que va creciendo hay que ir enrollando. $\mathrm{Y}$ el triple 15 , un fertilizante que se le pone, y hay que saber la medida porque si pone mucho se perjudica, si pone poco no sirve de nada... Y la mosca blanca... Este año ya se compró semilla, todavía no se plantó porque a principios de año mi marido entró a un crédito del gobierno, (...) hay muchos planes para los que quieren invertir en la chacra. Claro que ellos vienen a ver, no van a dar la plata a alguien que no puede devolver. Mi esposo por ejemplo lo gestionó con el título de la chacra en garantía, y le dieron un crédito para dos invernaderos.

Nosotros tenemos el problema del agua, con la sequía del año pasado que le contaba casi que nos quedamos sin agua... pero él inventó, que fue suceso para el que vino a ver de Posadas, del pueblo fueron a ver. Tenemos un arroyo a 500 metros, quedó chiquito de agua con la sequía, aunque tiene un caudal bastante grande. Entonces mi marido le cerró una parte del arroyo para que corra con más fuerza, hizo una rueda de madera, carpintero como es, y le puso. La cuestión es que tiene dos válvulas, que chupan el agua. Yo digo que parece un inflador, pasa por una manguera, compró 500 metros de manguera, y la rueda allá le fabricaron entre los tres, entre mi marido y mis hijos. La cuestión es que traían agua desde allá desde el arroyo hasta mi casa. Y le costó: fue controlando, cuanto venía en un minuto, en 15 segundos, hasta que mejoró. En 45 segundos vieron que llenaba una botella de un litro. Ellos anotan todo, mi esposo tiene un cuaderno de él donde anota, desde la primera vez que vinimos anota todo lo que hace en el día. El lleva un control de todo: es re ordenado este hombre. Hoy fecha tal, lluvia máxima, mínima, calor, sequía. El mide la lluvia, cuanto llovió cada vez... Todas las noches antes de dormir anota lo que se hizo, lo que no, la temperatura... Todo el mundo se admira de eso. Es para llevar un control de todo, porque vos decís: será que el año pasado cuanto llovió para esta fecha? Y llevas un control y más o menos podés saber. 
Como puede verse en el testimonio anterior y los que siguen, en este proceso de aprendizaje que iniciaron al trasladarse al campo, los distintos miembros de la familia fueron incorporándose en comunidades de práctica con vecinos, entre ellos, con técnicos agropecuarios, con docentes. La referencia de la madre de Simón a la introducción de cultivos no tradicionales en la zona muestra como, siendo relativamente novato en este mundo de plantadores, su marido puede dominar la actividad agrícola con rapidez dado que cuenta con un pequeño capital y la propiedad de la tierra, los que le permiten acceder a créditos y beneficios estatales.

Estas actividades que el grupo doméstico emprendió en conjunto responden al patrón tradicional de división sexual del trabajo. Por ello algunas tareas son inicialmente masculinas, cuando se vinculan con actividades productivas de valor en el mercado y una capacitación sistemática - como los cursos y posterior actividad de apicultura -; mientras otras actividades son por definición femeninas, cuando remiten a la reproducción domestica, como la huerta o la lechería de consumo familiar. No obstante estas responsabilidades prescriptas, el resto de los participantes se van incorporando a las tareas, de manera periférica en principio pero adquiriendo conocimientos que eventualmente pueden poner en uso. Así la madre de Simón ya conoce algunas enfermedades del invernadero, se ocupa ocasionalmente del procedimiento para disponer tutores en las plantas de tomates, y tiene cierta idea de la evolución de las cabezas de ganado.

La capacidad de Simón para proponer e incorporar en las actividades productivas del predio familiar ciertos conocimientos adquiridos en la escuela secundaria, se complementa con una apertura de los adultos para aceptarlos, en tanto procedentes de un ámbito experto como es la escuela secundaria de orientación agraria. Es posible hipotetizar que la discontinuidad intergeneracional dada por la biografía urbana de los padres de Simón otorgue una ventaja relativa a las jóvenes generaciones, ya que de los dos progenitores, solo el padre dispone de una relativa experiencia personal en un ambiente rural. Es por ello que la madre de Simón reconoce la complejidad de habilidades y conocimientos que proporcionó la escuela agraria a su hijo a través del dominio en el uso de fertilizantes y plaguicidas o incluso la construcción misma del invernadero.

Simón, sus hermanos y sus padres constituyen una comunidad de práctica donde el segundo de los hijos ocupa un lugar de relevancia en función del acceso a una educación especializada, pero que depende de la incorporación de su padre a las actividades para que estas se puedan llevar adelante. El progenitor asimismo ocupa un lugar central en la estructura de esta comunidad en tanto es capaz de generar conocimiento desde sus propias prácticas: es así como su esposa refiere extensamente al proceso de elaboración de un sistema de riego, asociado al control de temperatura y precipitaciones que efectúa cotidianamente su marido desde que se instalaron en el campo como parte del registro de actividades y acontecimientos del predio. Es significativo que la madre de Simón atribuya a este dispositivo el carácter de invención, ya que si bien los molinos son uno de los primeros instrumentos tecnológicos para el trabajo agrícola en la historia humana, en la experiencia personal del padre de Simón, y en la comunidad de práctica que constituyeron a los fines de instalar un invernadero, el problema de no contar con un abastecimiento regular de agua generó la búsqueda conceptual implícita en la construcción de un mecanismo, cuya ejecución incluye métodos de verificación y monitoreo de su funcionamiento.

\section{Simón en el invernadero}

En la visita al predio, Simón me muestra el invernadero en el que está trabajando, donde plantaron tomates hace tres meses. Explica cómo se utilizan los tutores de las plantas en función de la altura estimada de crecimiento, y los detalles de su evolución:

S: Acá está saliendo la flor, ya. De acá a dos meses justo, ya está madurando la fruta. Esta clase tiene que dar 10 coronas, aproximadamente. Cada corona da 5 a 7 frutos, así que tiene que dar más de 2 kilos por corona. Este tomate se le conoce como redondo, es la variedad coloso. Se lo riega a través de una cinta, cada 15 centímetros gotea el agua. (...) Se siembra en bandejas, speedling o bandejas multifaceta, cada bandeja tiene 128 celdillas. Se planta así porque la semilla es muy chica, se pone una en cada celda y 
uno trasplanta con un pan de tierra. Así se asegura el crecimiento de la planta.

E: y que cuidados tienen que darle?

S: Ahora estoy podando. Estos son chupones, brotes, que salen en cada hoja axilar. Esto se saca porque si no crece, incluso más rápido, que el cogollo. Lo que va a causar es demasiado volumen y no da fruto, o si da es demasiado chico, no es comercial. Entonces en vez de ser un beneficio que tenga varios brotes, varios ápices, es una pérdida. (...) Se riega una vez por día, casi siempre se controla el suelo. O sea, no es que si o si se riega una cierta cantidad por día. Si uno escarba un poco y ve que está un poco seco... Ahora por ejemplo, está especial. La tierra especial uno ((se da cuenta porque)) tiene que quedar así, sin chorrear. Ahí está ideal la humedad. De ahí un poco más, si es posible, pero el problema es cuando uno aprisiona, y se queda encharcada la tierra y chorrea agua, eso es demasiada agua. Y otra, si uno presiona la tierra, por ejemplo esto de arriba, y se desarma de vuelta, ahí falta agua. Esa es la técnica simple para cualquier planta, casi. Hay plantas, si, que ocupan mucha menos agua. Las ornamentales, por ejemplo, tienen menos agua que esta clase, apenas se humedece la tierra. Pero no es una planta hortícola, casi todas las plantas hortícolas tienen que tener ese punto de humedad en la tierra.

E: si no las enredas, que pasa?

S: ahí hay una que está sin enredar y esa está por caer. Lo que pasa cuando cae es que al tocar el suelo es más propensa a enfermedades. El fruto que toca el suelo queda manchado o se pudre directamente. La hoja que toca el suelo húmedo se pudre. Es un problema en invierno, en verano hay una zona en La Pampa, Córdoba, Santa Fe donde se planta tomate que no se usa el tutorado. Pero ese tomate no sirve para mesa, es solo para industria, para salsa, puré de tomate. (...) Se ata de bien abajo, de las hojas más gruesas. Es una medida bastante grande. Si uno se pasa de chico, la planta se estrangula, y si es demasiado grande, sale. Cualquiera de los dos extremos... ((Después está el tema de los plásticos, que se abren o cierran)) dependiendo de la temperatura adentro.

E: tenés un termómetro?

S: ahora a piel, nomas. El termómetro lo tenemos afuera, ahora que todavía no hace frío. No está helando. Cuando empieza a haber flores, la temperatura de acá dentro no tiene que bajar de 8 grados, si baja eso el polen queda inerte, la planta aborta la flor, entonces no da fruto. Ese es uno de los principales problemas, y el otro es el otro extremo, pasando de 34 o 35 grados el polen queda estéril, y también aborta la flor. El punto ideal para el cuajado de fruto, que la flor polinice el fruto, el polen quede estable y no se pierda, es entre 20 y 24 grados. (...) Dependiendo de qué tan alto uno levanta la cortina, si uno deja a la mitad, adentro puede seguir estando hasta 10 grados más que afuera, si uno abre totalmente está igual que afuera. Pero siempre está más caliente en la parte superior del invernadero, no tiene como escapar el aire.

En su explicación sobre el trabajo en el invernadero, Simón proporciona detalles de rendimiento, variedades utilizadas y métodos de siembra recurriendo a un lenguaje técnico y predominantemente impersonal. Sus tareas cotidianas son mencionadas esporádicamente, como cuando introduce los procedimientos de cuidado mediante la frase "ahora estoy podando", o cuando refiere al riego: "no es que si o si se riega una cantidad por día. Si uno escarba un poco y ve que está un poco seco...Ahora por ejemplo, está especial". Este último término condensa una serie de apreciaciones visuales y táctiles que Simón no puede traducir en palabras, que aprendió a reconocer en la escuela agraria y así puede usarlas, así como también transmitirlas a otros. Estas percepciones, no obstante, se integran en explicaciones y conceptos generales; por eso Simón extiende su afirmación: "casi todas las plantas hortícolas tienen que tener ese punto de humedad en la tierra".

En su recuperación de los conocimientos escolares en función de prácticas cotidianas, Simón también realiza traducciones entre la jerga especializada y los términos de uso cotidiano, como cuando muestra en las plantas de tomate: "estos son chupones, brotes”. Su participación es aún periférica en una comunidad de práctica donde sus profesores de la escuela agraria, los técnicos agrícolas a los que tiene acceso, y en términos amplios los productores -incluso de otras zonas del país- son fuente de certezas o reglas generales. En esa comunidad, que se puede encontrar distante en el tiempo y el espacio, Simón no solo comparte términos técnicos y jergas de la práctica, sino que aprende con el cuerpo: por eso sus manos pueden encontrar el punto justo para colocar los tutores 
o sentir "a piel" la temperatura adecuada para la cobertura del invernadero.

Además de las consideraciones anteriores, Sergio relata sobre los sistemas de calefaccionado, la duración de la estructura del invernadero y el incipiente conocimiento sobre métodos de fumigación y tratamiento de enfermedades, sobre los que debieron recurrir a un técnico del Instituto Nacional de Tecnología Agropecuaria. Explica que en el vivero se dedican a plantar tomates porque lo aprendió en la escuela agrotécnica, pero también porque evaluaron que es un producto fácilmente comercializable, si bien tiene actualmente el estatuto de proyecto complementario dentro de la estrategia económica de su familia, cuyos ingresos provienen de la carpintería, y en un futuro de una pequeña explotación forestal asociada:

\section{E: por que decidieron poner tomate?}

S: una porque yo me especialicé en tomate, al menos en la escuela secundaria, en la escuela agrotécnica. $Y$ otra que tiene bastante salida. No es muy dificil vender, que es el principal problema casi siempre. (...)El tomate en si es un proyecto alternativo acá en la chacra, nuestra principal entrada económica es la carpintería, el segundo es el tomate. Nosotros no tenemos aserradero, forestamos un pedazo, una parte de la chacra, pero falta bastante para poder tumbar los árboles. Plantamos un poco de pino y hoveña, o palito dulce como le conocen por acá (hovenia dulcis, planta exótica originaria de Asia). Es una madera dura, casi siempre se usa para parquet, y también se hacen mesas, muebles, placares. Es como el algarrobo. Ya 10 años hace que plantamos, pero faltan 10 años más para tumbar. El pino también hay que esperar, se saca raleado a los 10 años. El raleo es solo para pasta. Se va a vender a Papel Misionero, que es lo que queda más cerca, en Puerto Piray. Eso es todo para hacer pasta celulosa. El resto, para que sea aserrable, hay que esperar otros 10 años más. (...) Con pino de 18 años se puede estar vendiendo madera. $Y$ si uno espera 50 años puede laminar y hace terciado, sale más caro. Nosotros plantamos un cuarto de hectárea con pino, porque a mi papá no le gusta el pino para trabajar, a mi tampoco. Es bastante fea la madera, empasta todas las maquinas. Para aserrar no hay problema, los aserraderos ya tienen maquinas especiales para el pino. Pero nosotros en la carpintería trabajamos con madera dura, nos empasta la maquina una madera exageradamente blanda como el pino. En cambio de hoveña hay 2 o 3 hectáreas.

En su reflexión acerca de la producción de madera, Simón también recurre a la alternancia entre los términos técnicos y de uso práctico: "Plantamos un poco de pino y hoveña, o palito dulce como le conocen por acá”. En este caso, la referencia a la comunidad de práctica es sensiblemente distinta: su padre y él, en tanto carpinteros, comparten una ponderación diferencial de ambas especies en función de su uso en el taller, mientras que el tono impersonal alude a una práctica futura de la cual tiene conocimiento solo de oídas, aun, y que incluye a otros actores, en este caso a una escala industrial.

\section{La escuela agrícola y los proyectos de futuro}

Simón cursó los tres primeros años de la escolaridad secundaria en una escuela de gestión privada y confesional de bajo costo, pero su familia no pudo afrontar los gastos por lo que este joven pasó a cursar los dos últimos años en una escuela pública agrotécnica a la que accedió becado. No obstante su interés por las actividades agrarias y que ambos establecimientos eran de la misma especialidad, Simón no logró obtener el certificado de estudios secundarios porque el plan de estudios era diferente, y en 2010 debía tres exámenes.

En su relato retrospectivo, el joven reconoce que la escuela agrotécnica le proporcionó conocimientos que se anclaron en lo que ya había aprendido en la chacra, y proyecta realizar sus estudios superiores en la misma línea. Es en esta continuidad de actividades productivas que establece dos contrastes interesantes: el primero respecto de su vida improductiva urbana -donde se presenta a sí mismo frente a la televisión-, y su llegada al campo -donde esos entretenimientos no estaban disponibles pero también, donde el grupo doméstico necesitaba de su colaboración-. Una segunda oposición, más reciente, lo enfrenta con algunos de sus compañeros de estudios secundarios distinguiendo a quienes, resignados, consideran que el estudio excede sus necesidades como futuros obreros rurales y a la vez de quienes, ambiciosos, piensan el trabajo en el campo como sinónimo de atraso: 
S: antes salía de la escuela y me sentaba a mirar televisión, en Iguazú. Cuando se vino para acá... ahí hay que hacer algo, una que no teníamos televisión, no había luz. Y otra que ya éramos bastante grandes, así que bien podíamos ayudar. Yo tenía 9 años, pero ahí a esa edad no hacía casi nada. A los 12 empecé a trabajar más o menos. Yo siempre ayudé a papá en la carpintería. Hicimos la casa, después se criaba animales, se carpía. De lo que sea de chacra fui aprendiendo todo... empezamos a plantar, aprendí lo que es una azada, aprendí lo que es una plantadora. (...) Y después lo que sea desmalezamiento: carpida, macheteada.

\section{E: como ibas aprendiendo?}

S: Mi papá primero dice que hay que hacer, uno empieza a hacer y él mira si estamos haciendo bien... y ahí recién se va. Se aprende de a poco. Pero yo creo que el tema de aprendizaje está en cada persona. Yo conozco muchos que trabajan en la chacra, algunos estudian, otros no... eso está en cada persona. Es difícil influenciar, en una familia, que un chico trabaje y estudie al mismo tiempo. Mire que yo traté... hablaba con mis compañeros y todo eso: los que no querían estudiar, directamente decían "que voy a estudiar acá si voy a salir carpiendo!" esa era la mentalidad que tenían... O sea, estudiar tanto, romperse la cabeza, para terminar siendo peón de... trabajador rural. Esa era una de las tantas mentalidades que siempre van para abajo. Y otros que sí estudian, pero no quieren saber nada de la chacra. Es el otro que perjudica; no saben valorar el trabajo en sí. Quieren vagar, el boliche, para ellos es diversión tomar alcohol, hasta que no estén panza arriba tirados en la calle no es joda. Hay muy pocas personas que quieren seguir adelante, ser alguien en la vida al menos. A mí me costó, quiero seguir estudiando... no sé cómo voy a hacer, pero voy a seguir estudiando. Ingeniero Agrónomo, Técnico Superior Forestal, lo que sea de chacra.

En el primer contraste es significativo el matiz que establece Simón respecto de las actividades productivas en relación a las edades: si bien la infancia en el ambiente rural le impuso obligaciones, estas fueron progresivas y se incrementaron en coincidencia con la finalización de la escuela primaria; en este punto conviene recordar las posiciones regulacionistas en torno al trabajo infantil, que permiten ponderar el trabajo predial y distinguirlo del empleo asalariado encubierto. Asimismo el testimonio de Simón refleja el proceso de adiestramiento de manera general, ya que el padre es retratado observando las actividades de sus hijos para que estos se autonomicen gradualmente.

Por otra parte, el segundo contraste que establece Simón respecto de sus compañeros de estudios en la escuela agrotécnica es fructífero para reflexionar sobre los procesos de estratificación social y las promesas de la escuela rural desde la perspectiva de los jóvenes. Para algunos, el conocimiento escolar no tiene valor porque sus proyecciones de futuro no necesitan de certificaciones y están alejadas de aquello que se estudia en la secundaria: se imaginan en empleos manuales de baja calificación en el campo como sus padres. Para otros, es el trabajo predial el que no tiene valor: sus proyectos de futuro se vinculan con el conocimiento del mundo urbano $-\mathrm{y}$ con sus actividades sociales vinculadas al ocio -. El hecho de que Simón se distancie de unos y otros implica, desde mi punto de vista, que los sujetos pueden desafiar el destino que la posición estructural le permite anticipar.

En su persistencia para continuar su educación formal en el Nivel Superior, Simón reconoce la importancia del estudio, pero también de la transmisión desde la práctica, sea esta en el contexto escolar como en el predio familiar. Esas actividades son el marco donde puede transmitir a su padre y a alumnos de menor edad los conocimientos adquiridos:

Este es el tercer año que no estudio. Pero uno sigue leyendo, sigue estudiando por más que no vaya al colegio. Hay que seguir leyendo, seguir aprendiendo... Lo que sean enfermedades del tomate casi de memoria las conozco. Le puedo nombrar todos los químicos que yo pongo, todas las enfermedades por las que ya pasé... Yo fui quien le dije a papá, él quería hacer invernadero pero no tenía ni noción de como se hace el tomate. Y uno en la escuela aprende las medidas, el plástico que se usa, todo lo que sean la medida entre plantas, las fechas. Al estudiar lo que sea plantación, uno primero que todo tiene que ver el terreno, la orientación del sol, si hay agua, si no hay agua. Si el terreno no tiene desnivel, no tiene pendiente. Todas esas son cosas fundamentales, que uno solo no las aprende. Si o si necesita de alguien que sepa o... Incluso un libro no va a explicar tanto como lo que es hacer, y en la escuela agrotécnica uno hacía. A mí me dieron el invernadero de allá para que yo lo atienda. ((Lo hacía)) casi solo, porque me daban un grupo de gurisada, pero cuando 
yo me agachaba a sacar un brote, me levantaba y había menos. Y cuando me daba cuenta había uno o dos chicos... (...) No estaba yo solo, estaban los instructores. Los chicos eran de cursos inferiores, había algunos que estaban ahí porque la mamá les manda, les dejan presos, digamos... y están los que verdaderamente quieren aprender. Te preguntan qué hacer, como ayudo. Esos son los que vale la pena destacar. Y están los que están esperando que vos mires para otro lado para mandar pata. Pero no estaba solo, estaba el supervisor mirando.

Tal como anticipa el concepto de aprendizaje situado, Simón ve crecer su conocimiento sobre enfermedades y productos químicos a través de lo que lee y de sus experiencias cotidianas. Con su testimonio es posible complejizar la idea del sentido común de que la escuela transmite un conocimiento teórico mientras en el campo se adquiere un conocimiento práctico: lo que Simón aprende es relevante porque él atiende el invernadero y transmite a otros, trabajando, en la escuela. Pero ese conocimiento crece cuando Simón usa, con su padre, esos aprendizajes en el predio familiar.

\section{Conclusiones}

La normativa internacional relativa al trabajo infantil y juvenil ha constituido un avance innegable en la defensa de los derechos de las jóvenes generaciones. No obstante, las posiciones regulacionistas ya hace más de diez años advierten sobre la necesidad de contemplar los aprendizajes que, enmarcados en actividades cotidianas vinculadas a la reproducción de los grupos domésticos, son soslayados es pos de la protección de niños y adolescentes.

Una de los argumentos más consistentes para las posiciones abolicionistas consiste en atribuir al trabajo de niños y jóvenes la causa del fracaso, el abandono y las discontinuidades en la escolarización. No se trata de ignorar que en muchos casos se trata, efectivamente, de situaciones de empleo precario donde los niños son sometidos a actividades agotadoras que no involucran aprendizajes significativos. No obstante, en este artículo he pretendido demostrar que, en ciertos casos donde el trabajo a cargo de los niños y jóvenes es progresivo, asociado a la producción predial diversificada, en condiciones de vida relativamente estables y articulado a una educación orientada a las actividades agrarias, el trabajo predial no solo no obstaculiza la escolarización sino que la amplifica en sus alcances.

El trabajo agrícola le ha permitido al joven cuya experiencia ha sido analizada, profundizar procesos de conocimiento originados en el contexto escolar. Asimismo le ha permitido constituir comunidades de práctica diversas vinculadas con las diferentes actividades productivas, donde los adultos y otros jóvenes son participantes con distinto grado de responsabilidad, habilidades y dominio de conocimientos conceptuales. El adiestramiento, entendido como un aprendizaje desde la actividad, incluye contextos escolares y no escolares: el joven hace en la escuela agraria, hace en el predio familiar, y mientras hace los alumnos menores a él, pero también sus padres, aprenden de su hacer.

Simón domina un conocimiento técnico relativo a ciertas actividades agrícolas, que incrementa aun habiendo finalizado los estudios formales. Establece lazos entre ese conocimiento experto y la jerga constitutiva de las prácticas sociales: traduce términos y procesos, aprendizajes corporales y percepciones sensoriales en términos que no pueden comprenderse sino es en relación al contexto de prácticas en que se producen, pero que no por ello son menos abstractos. Sus intenciones de aprender lo muestran como un sujeto activo, en permanente reflexión, y no un estudiante que ha fracasado en términos de no haber logrado la certificación de Nivel Medio.

No obstante, su situación dista de ser idílica: tanto Simón como su familia tienen limitadas posibilidades de incrementar y mejorar su producción predial, y con ello sus condiciones de vida y conocimiento del mundo social y natural. Su situación como colonos es relativamente acomodada si se la compara con familias de ocupantes y las comunidades indígenas cuya situación en términos de condiciones de vida y posibilidades de transmisión intergeneracional de conocimiento cultural es grave. Pero por otra parte, y como he mostrado al comienzo del trabajo, el proceso de concentración de la propiedad de la tierra acaecido en las últimas décadas no parece augurar un crecimiento de estos pobladores definidos como colonos sino, por el contrario, un incremento de su migración a las ciudades. 


\section{REFERENCIAS}

BARANGER, DENIS. La construcción del campesinado en Misiones: de las Ligas Agrarias a los "sin tierra", En: Campesinos y agricultores familiares: la cuestión agraria en Misiones a fines del siglo XX. Editado por G. Schiavon., Buenos Aires: Ciccus, 2008. p. 33-70.

BARTOLOME, Leopoldo. Los colonos de Apóstoles: estrategias adaptativas y etnicidad en una colonia eslava en Misiones. Posadas: Universidad Nacional de Misiones, 2000.

BARTOLOMÉ, Miguel. Flechadores de jornales: identidad guaraní en el Paraguay contemporáneo.. Les Cahiers ALHIM, v.10, n.2, fév. 2004. Amérique Latine Histoire et Mémoire Disponible en: http://alhim.revues.org/index120. html. Consultado el: 27 mayo. 2009.

BIDASECA, Karina y MARIOTTI, Daniela. Viejos e nuevos actores en la protesta rural en la Argentina. Sociologías, Porto Alegre, v.3, n..5 p.148-189. 2001.

CRAGNOLINO, Elisa. Infancia, escolarización y apropiación de la lectura y la escritura en familias rurales. En: XI SIMPOSIO DE INVESTIGACIÓN ETNOGRÁFICA EN EDUCACIÓN.11., 2006, Buenos Aires. Actas.... Buenos Aires: UBA. 1 CD-Rom.

CENTRO DE TRABALHO INDIGENISTA, Guarani Reta. Coordinación General del Proyecto: Grunberg, G. ; Macedo, C. Brasilia: [s.n.], 2008.

FERRERO, Brian. Territorios ambientalistas e identidades rurales: el caso de los colonos de Misiones, en el noreste argentino. En: REUNIÓN DE ANTROPOLOGÍA DEL MERCOSUR. 6., 2006. Montevideo. Actas... .... Montevideo: Universidad de la República, 2007. 1 CD-ROM.

ARGENTINA. GOBIERNO DE MISIONES. Anuario Estadístico. Posadas: Instituto Provincial de Estadísticas y Censos, 2008.

GORDILLO, Gastón. Después de los ingenios: la mecanización de la zafra saltojujeña y sus efectos sobre los indígenas del Chaco Centro-Occidental. Desarrollo Económico, Buenos Aires, v.35, n. 137, p. 105-126, 1995.

GOROSITO, Ana. Liderazgos guaraníes, breve revisión histórica y nuevas notas sobre la cuestión. En: REUNIÓN DE ANTROPOLOGÍA DEL MERCOSUR, 6.,2006, Montevideo. Actas... Montevideo: Universidad de la República, 2007. 1 CD-ROM.

JACQUEMIN, Melanie. Children domestic work in Abidjan. Cote D'Ivoire. Childhood, v. 11, n. 3, p. 383-397. 2004.

JAUME, Fernando et al. Notas sobre la historia de Misiones: el Proceso de formación de la región histórica. Posadas: PISPAD, 1989.

LAVE, Jane y WENGER, Etienne. Situated learning: legitimate peripheral participation. Cambridge, England: Cambridge University Press, 2007.

LEITE DE SOUSA, Emilene. Que trabalhais como se brincásseis: trabalho e ludicidade na infância Capuxu. 2004. 106 f. Tesis (Maestría) - Programa de Posgraduación en Sociología, Universidad Federal de Paraíba, 2004.

LEVINSON, Bradley y HOLLAND, Doroty. The cultural production of the educated person: Critical ethnographies of schooling and local practice. New York: State University of New York, 1996.

MANZANAL, Mabel y ROFMAN, Alejandro. Las economías regionales de la Argentina: crisis y políticas de desarrollo. Buenos Aires: CEAL, 1989.

NEIMAN, Guillermo et al. Al campo siempre lo ayudo con otra cosa. Buenos Aires: CEIL-PIETTE-CONICET, 2002. Documento de trabajo n. 40.

NIEUWENHUYS, Olga. The Paradox of Child Labor and Anthropology. Annual Review of Anthropology, v.. 25, p. 237-251. 1996.

NEVES, DELMA. A perversão do trabalho infantil: lógicas sociais e alternativas de prevenção. Niterói: Intertexto, 1999.

NOELLI, Francisco Silva. La distribución geográfica de las evidencias arqueológicas guaraní. Revista de Indias, v.64, n. 230 , p.7-34. 2004. 
NOVARO, Gabriela et al. Niños indígenas y migrantes: tensiones identitarias, experiencias formativas y procesos de escolarización. Buenos Aires: Biblos, 2011.

ORGANIZACIÓN INTERNACIONAL DEL TRABAJO. Trabajo infantil indígena. una aproximación conceptual. Lima: Programa Internacional para la Erradicación del Trabajo Infantil ,2009.

OTERO, Natalia. De la chacra al corte: los dirigentes de Unión Campesina y la lucha por la tierra en el nordeste de Misiones. En: Campesinos y agricultores familiares: la cuestión agraria en Misiones a fines del siglo XX. Editado por G. SCHIAVONI. Buenos Aires: Ciccus, 2008. p..71-98

PADAWER, Ana. La protección de los derechos de la infancia mbyá- guaraní: aportes de la etnografía en la problematización de las experiencias formativas. Espaço Ameríndio, Porto Alegre, v. 4, n. 2, p. 52-81, jul./dez. 2010.

RAMOS, Ana 2006. 'Proyectos sustentables' y 'nichos de mercado' entre hegemonías situadas. En: CONGRESO ARGENTINO DE ANTROPOLOGIA SOCIAL,7., 2006. Salta. Actas... Salta: UNSa, 2006. 1 CD-ROM.

RENDE TAYLOR, Lisa. Dangerous Trade-offs: the behavioral ecology of child labor and prostitution in rural Northern Thailand. Current Anthropology, v. 46, n. 3, Jun. 2005.

REBORATTI, Carlos. Migraciones y frontera agraria: Argentina y Brasil en la cuenca del Alto Paraná-Uruguay. Desarrollo Económico, Buenos Aires,v. 19, n.74, p.189-209. 1979.

RICOTTO, Alcides y ALMEIDA, Jalcione. Las ferias francas de Misiones, Argentina: una red de actores sociales y una nueva visión del mundo rural. En: CONGRESO DE LA ASOCIACIÓN LATINOAMERICANA DE SOCIOLOGÍA RURAL,6., [2002], Porto Alegre. [Anais...[ Porto Alegre, [2002]. Disponible en http://www.ufrgs.br/ pgdr/textosabertos/artigo\%20ricotto.pdf. 2002.

ROGOFF, Barbara et al. Guided participation in cultural activity by toddlers and caregivers: Monographs of The Society for Research in Child Development, v. 58, n. 8, 1993.

SCHIAVONI, Gabriela. Colonos y ocupantes: parentesco, reciprocidad y diferenciación social en la frontera agraria de Misiones. Posadas: Editorial Universitaria de Misiones, 1995.

SCHIAVONI, Gabriela. Nuevas organizaciones agrarias: plantadores y campesinos en el nordeste de Misiones, En: Campesinos y agricultores familiares: la cuestión agraria en Misiones a fines del siglo XX.. Editado por G. Schiavon., Buenos Aires: Ciccus. 2008. p. 99-132.

VAN DER VEER, René y VALSINER, Jaan. Vigotsky: uma sintese. Sao Paulo: Loyola, 2006.

VYGOTSKY, Lev The problem of environment. En: VAN DER VEER, René y VALSINER, Jaan: Vigotsky:a reader. Oxford: Blackwell, 1994.

WENGER, Etienne. Comunidades de práctica. Barcelona: Paidos, 2001.

WOODHEAD, Martyn. Psychosocial impacts of child work: a framework for research, monitoring and intervention.[S.1.]:UNICEF/ World Bank, 2004. (Understanding Childrens work Project. Working Paper Series). 